his special acquaintance with mental philosophy and medical psfchology; his practical training in the treatment of mental disease, during five years as resident physiciai in an extensive public lunatic asylum; from five years' employment as a lecturer on mental disease in the University of AberdeenKing's College; and, lastly, after carefully perusing his admirable lectures on the medical jurisprudence of insanity, published in the London Mredical Gaztte for 1850. Influenced by these testimonials, in addition to Dr. Jamieson's acknowledged scientific attainments, age, and general experience, $I$ therefore voted for him, as he appeared, according to my judgment, in every way able to superintend such an institution as Bethlem Hospital, and also to augment its usefuiness as a school for the instruction of students anxious to obtain practical information regarding the nature, treatment, and pathology of mental diseases, in which important subjects, other governors, like myself, have, during late years, taken much interest.

Brook-street, July 12, 1852.
I remain, Sir, yours faithfully,
JowN WEBSTER.

TO THE GOYERNORS OF THE ROYAL HOSPITAL OF BETHLEM.

My Lords and Gentrenen.-The appointment made yesterday, of the Resident Physician to this Hospital, leaves me no alternative but respectfully to tender $m y$ resignation of the office I now hold in this institution. For more than seven of the best years of my life, which have been passed in this hospital, in the anxious endeavour to cerform, as far as was practicable, the very onerous duties which devolved upon me, I have betn the superior resident officer; and practically, although not nominally, the resident physician. I have had to contend with difficulties which have never been appreciated; I have been opvressed with an amount of labour, of ceaseless anxiety, and overwhelming responsibility, which has been carried to the very verge of human endurance, and which, I believe, is without parallel in any other official position in the kingdom. With very limited authority and no assistance, I have struggled to promote the welfare and happiness of those committed to my charge; and it is a deep satisfaction to me to know that my labours have not been in vain, and that they have been recognised in such flattering terms by those who have had constant opportunities of observing the manner in which I perfurmed the arduous duties of my responsible office. The testimonials which were submitted to your committee, and publicly acknowledged in the court to be far superior to those of any other candidate, are sufficient proof of the reputation I have earned in my profession. This reputation $I$ cannot now afford to sacrifice by holding office under a gentleman so many years my junior, of whom, personally, I desire to speak only in the kindest terms, but of whom it cannot be contended that he has any one professional claim to be considered my superior.

In yielding to the powerful influence of my successful competitor, I am unwilling that the institstion should suffer from being suddenly handed over to strangers, and I desire to express my wish that such further use may be made of my services as may be considered advantageous to the patients, to the hospital, and to my successor.

I have the honour to be, my Lords and Gentlemen, Your very faithful Servant,

Bethlem Hospital, 13th July, 185 ?.

W. Wood, M. D. Licentiate of the Royal College of Physicians.

\section{ON THE TRANSMISSION OF LIQUID VACCINE LYMPH.}

To the Elitor of The Lancer.

SrR,-May I beg the favour of informing Mr. Chatterley and the profession, through the medium of your valuable journal, of a simple and efficient method of preserving raccine lymph I have been in the habit of using for the last thirty years, possessing, 1 think, many advantages, not the least of which is, being free from the risk of decomposition.

I obtain from any of the glass-workers the little bulb known in toy-shops by the name of "candle-bomb," before it is filled with the water which causes the explosion, and, after softening the stem with the blow-pipe, or flame of a spirit-lamp, I draw it out to from three to four inches, and break off the extreme point; it is then fit for use. By applying the tongue or the warm fingers to the bulb, the air is rarefied and partially expelled. The poin should then be immediately inserted into the recently punctured resicle, when, as the bulb gradually cools, the lymph will be seen to rise in the capillary tube from the partial vacuum produced; it must then be immediateiy sealed. which is easily done by fusing and twisting the point. I generally use the flame of an ordinary candle for the purpose, that being always at hand. The little instrument, so charged with raccine lymph. and secured immediately by hermetically sealing, may be safely relied upon for years.

I have repeatedly sent it to the West Indies, packed in these tubes, with perfect suecess; and, in order to test the condition of the lymph so preserved, vaccinated many patients at the St. James's Infirmary most satisfactorily, at a time of severe epidemic small-pox in the parochial schcol adjoining, when there was great difficulty in obtaining fresh vaccine lymph. In no case was there ever any accident followed the use of $1 \mathrm{ymph}$ so preserved; and, in one case, which was just as successful as the rest, the vaccine lymph had been thus protected for three years.

I have for many years been in the habit of making these tubes for myself; but formerly Pastorelli, or Cross-street, Hatton Garden, used to make them for me, at $2 \mathrm{~s}$. $6 \mathrm{~d}$. per dozen.

Should you feel this communication of sufficient interest, would you be pleased to insert it in your valuable work?

Vigo-striet, July 14, 185?. I am, Sir, yours faithfully,

\section{ALLEGED QUACKERY IN WINDSOR CASTLE. To the Editor of 'THE IAANCET.}

Sir,-It has always been part of the tactics of the homœopathists to assume to themselves the countenance and support of the aristocracy, and at their meetings to assert boldly, that "Her R.H. This and His Grace the Duke of That" had become converts to their humbug, on the same principle that Holloway and $\mathrm{Co}$. parade their wonderful cures to catch the unwary, knowing full well how seldom such assertions will be contradicted; but $I$ have not seen the Queen and her household dragged into their advertisements of this kind until to-day.

The Halifax Guardian, in reporting a homœopathic dinner, held at Huddersfield, the stronghold of globulism in the West Riding, states:-"The Chairman, (J.Stansfeld, Esq., of HIalifax,) in proposing the Queen, Prince Albert, and the Royal Family, spoke in elegant terms, and took occasion to allude to the fact, that the royal children are always treated homoopathically, as well as most of the members of her Majesty's household."

Now, Sir, will you be kind enough to tell the profession if such an assertion has any foundation, and, if so, ask Sir James Clark, Mr. Brown, of Windsor, and the other medical attendants of the royal household, if such treatment is sanctioned by them?

July, $18 \overline{2}$.

I am, Sir, your old correspondent, Antr-Humbug.

* * We publish this note from a practitioner of great respectability, and we feel confident that Sir J. Clark or Mr. Brown will feel it to be necessary to denounce the calumny uttered by the impertinent homœopathic spouter at Fudders. field.-ED. LANCET.

\section{DR. GREGORY AND THE PROMOTERS OF SMALL-POX. \\ To the Editor of The LANCET.}

Sir,-I cannot express too strongly my feelings against the assertion put forth by Dr. Gregory, that inoculation by smallpox should not be interdicted by a special law. He says that no one ever had nor ever will have secondary small-pox -an assertion on which he builds his theory, and on which he would found his practice. I can tell him that his house is built upon a sand rock. I have seen secondary small-pox. I have at this moment under my care a man with small-pox, who before this attack was fully and distinctly marked, and, if need be, I can bring proof that he really has had the disease. Dr. Gregory will say that either the first attack was doubtful, or that the present one is, and so will escape by a mere shuffle.

Dr. Gregory says that vaccination, if properly performed, can never be followed by small-pox. This is also a mistake; for there are many, very many persons who have been well vaccinated, who have the disease, and badly too. I may appear to be arguing against the efficacy of vaccination; but it is not so. I have for ten years vaccinated most extensively, both in Loudon and the country, and my experience has shown me the perfect harmlessness of the remedy, and its great power of protection in preserving whole districts from the disorder. No 